\title{
Parametric Investigation of the Effects of Localization and Slenderness on the Stress-Strain Response and Confinement Efficiency in FRP-Wrapped Concrete Cylinders
}

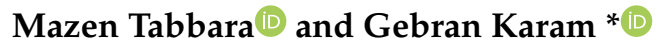 \\ Department of Civil Engineering, Lebanese American University, Byblos P.O. Box 36, Lebanon; \\ mtabbara@lau.edu.lb \\ * Correspondence: gkaram@lau.edu.lb; Tel.: +961-1204959; Fax: +961-1336399
}

Received: 5 April 2020; Accepted: 8 May 2020; Published: 15 May 2020

Featured Application: The work presented clarifies the mechanical principles and efficiency by which the passive confining device strengthens concrete and confirms the capabilities of the shear-friction analysis for the FRP-confined members. The results and proposed model can be used to improve the design recommendations of ACI for the FRP strengthening of concrete members subject to axial and combined forces.

\begin{abstract}
In order to improve the efficiency of fiber reinforced plastics (FRP) confinement as a method to repair and strengthen concrete structures, a parametric analysis was carried out to investigate the effects of cylinder slenderness and the stiffness of the confinement on the localization pattern, the stress-strain response and the effectiveness of the confinement. FRP-wrapped concrete cylinders under axial compression were modeled in a high-resolution finite element model. Concrete was modeled as a Mohr-Coulomb material. The bi-linear stress-strain structural responses concur with published experimental data. Localization along discrete shear planes results in a failure mechanism that causes non-uniform hoop stresses in the FRP wrap due to the movement of solid wedges in the mechanism. A characteristic length for localization was identified and found in agreement with published experimental observations. The confinement efficiency shows a clear dependence on the confinement level and a weak dependence on slenderness above the characteristic length. A simple mechanistic model is proposed for the second branch of the bi-linear stress-strain response curve. The results of this study can be used to estimate the confinement efficiency factor and refine the design recommendations of Equation 12.1 of ACI 440.2R17.
\end{abstract}

Keywords: confined concrete cylinders; FRP wraps; stress-strain; slenderness; localization; characteristic length; confinement effectiveness; Mohr-Coulomb material; shear-friction analysis

\section{Introduction}

The confinement of reinforced concrete columns in aging infrastructure with multiple layers of fiber reinforced plastics (FRP) has gained wide acceptance as a repair and strengthening method and considerable experimental and theoretical research has been devoted to the topic during the last 30 years. International and national organizations have issued standards and technical recommendations for the use of FRP wraps to reinforce concrete columns, such as in ACI 440.2R17 [1] and CS806 [2], reflecting the state of the art. The strengthening effect is achieved by the passive resistance that the elastic FRP confining wrap offers to the lateral expansion of concrete under compression. In spite of 
multiple research efforts, no unified model has been established to predict the stress-strain response of FRP-confined concrete or to predict its failure strength.

Several models, mostly empirical in nature, were proposed in the literature to simulate the apparent stress-strain or structural response of the FRP-confined compression sections, such as Teng et al. [3], De Lorenzis and Tepfers [4] and Lam and Teng [5], to cite some of the earliest. These models have been calibrated against the authors' own sets of experimental data showing limited predictive capabilities for other data sets $[4,6]$. The bi-linear stress-strain model by Lam and Teng [5,7] for FRP-confined concrete was adopted in ACI 440.2R17 [1] and the design formulae were also recommended based on a modified form of the same model. One of the main shortcomings encountered by the proposed models and the published design recommendations is the difficulty in determining the actual failure strain of the FRP wrap and hence the effective confinement pressure. In closely monitored experiments, the FRP confining device is observed to fail at lower average strains than those measured for FRP tensile coupons, of the order of $50 \%$ to $80 \%$, therefore providing a proportionally reduced confining stress [5,7-25]. ACI 440.2R17 [1] has adopted a bi-linear stress-strain relationship for FRP-confined concrete and recommended the use of a conservative strain efficiency factor of 0.55 for the FRP in order to estimate the confinement stress. A minimum confinement ratio of 0.08 of the unconfined compressive strength was recommended by ACI 440.2R17 to ensure a non-descending second branch in the stress-strain response diagram. This suppression of softening was discussed in detail in Moran and Pantelides [26] and Moran et al. [27].

Different explanations have been proposed for the low average failure strain of the FRP wraps, the most plausible being that stress concentration regions caused by cracking and dilation of the concrete lead to the development of local stress concentrations in the FRP wraps [5,7-25]. Using numerical modeling, the authors showed that the hoop strain distribution along the height of the cylindrical concrete specimens was not uniform. Their results suggested that localization and the development of a failure mechanism in concrete caused the development of stress concentration zones where the ultimate FRP strain was reached, thus resulting in premature failures, as was noted in experimental observations [28]. Using a photogrammetric digital image correlation technique (DICT) that allows capturing strains from the surface of the FRP-confined concrete, Bisby and co-workers $[16,17,20]$, El-Hacha and co-workers [19,21,23] and Wei and Wu [29] measured the non-uniformity of the hoop strains across the height of the tested concrete cylinders and the sharp rise of these strains points to localized failure. Extensive arrays of electrical resistance strain gauges were also utilized by other researchers $[18,22,24]$ to confirm the non-uniform distribution of the hoop strains in the FRP along the height of the cylindrical concrete samples, and the localization of failure. Teng et al. [25] discussed the non-uniform distribution of hoop strains in the FRP wraps of elliptical section columns and numerically modeled the experimental results to propose a stress-strain model for the structural response of the columns.

The effects of specimen slenderness, which represents a relevant parameter of the problem, have been known for a long time [30-35] and were at the basis of selecting a height to diameter H/D ratio of 2 for the standard cylinder used for testing unconfined compressive strength.

Finite element models have been used over the last twenty years to model the structural response of FRP-confined concrete sections of various geometries and types of reinforcement and confinement with two objectives: (i) modeling the apparent stress-strain relationship or structural response of the confined concrete columns, as well as (ii) predicting the failure load and mode of failure [36-60]. The most popular FEM software package used was ABAQUS, for its choice of standard material models and the flexibility offered by its materials' subroutine [38,42-44,48,51-56,58-60]. Other FEM codes were also used, such as ANSYS [39,57], LS-DYNA [45], DYNA3D [37], PRECON3D [41] and MASA [46]. The key, however, to modeling the complex behavior of concrete is the choice of material model, and many models have been used, with the Drucker-Prager $[40,47,48,57]$ and Concrete Plasticity Damage models [42,51,54-56,58-60] being the most popular; in addition, Mohr-Coulomb has been used [41], a microplane material model has been used [46] as well as an adapted CAM-CLAY model [53]. Most of 
the proposed models achieved acceptable to good agreement with experimental data and contributed to the understanding of the field; however, many of these models are highly elaborate or were developed for particular geometries and conditions. It was noted that a limited number of publications have addressed the localization of failure in confined concrete, its effect on the failure of the FRP wrap and, consequently, the confinement efficiency [16-24,29].

Given the nature of the problem, the need for a simple FEM approach with a simple material model that allows the study of localization and failure, without the complex refinements particular to plasticity and damage models, was identified and considered in this work. In order to investigate the relationship between localization, failure mode and the observed structural response, a parametric numerical investigation into the behavior under compression of concrete cylinders wrapped with CFRP was carried out and is presented in the remainder of this paper. The number of wraps as well as the slenderness of the cylinders wereas varied and the following results are presented and discussed: (i) the stress-strain or structural response curve; (ii) the CFRP hoop strain profiles; and (iii) the principal strains inside the concrete showing localization patterns.

A simple mechanistic model is also proposed to model localization and the second branch of the bi-linear structural stress-strain response. A modification to the design equation for Equation 12.1 in ACI 440.2R17 [1] is proposed, taking into account the slenderness effects and the level of confinement.

\section{Materials and Methods}

\subsection{Finite Element Program}

The Finite Element package PLAXIS V8 [61] was used to simulate the response of concrete cylinders wrapped with FRP under axial compression. PLAXIS has high-resolution triangular elements that can capture the location and extent of the strain localization in shear bands; it also has geogrid elements that can sustain membrane tension only to model the FRP wrap. For the parametric study, the cylinder diameter, $\mathrm{D}$, was maintained at the standard $150 \mathrm{~mm}$ while four cylinder heights, $\mathrm{H}$, were investigated: 150, 300, 600 and $900 \mathrm{~mm}$, corresponding to the slenderness ratios, H/D, of 1, 2, 4 and 6 , respectively. The effects of the 1,2, 4 and 6 wrap configurations were also investigated using the properties of the Sika Wrap Hex 230C [62], which was used in the preparation of the reference concrete cylinders tested for model calibration.

\subsection{Finite Element Mesh}

An axisymmetric mesh with high-resolution 15-node triangular elements was used to model the concrete and 5-node geogrid line elements were used to model the FRP wrap. Geogrids are slender structures with axial stiffness but with no bending stiffness. In addition, geogrids can only sustain tensile forces and no compression. This behavior is well suited for modeling the FRP wraps. Four axisymmetric meshes were generated, one for each of the cylinder heights: 150, 300, 600 and $900 \mathrm{~mm}$. The deformed mesh shown in Figure 1 presents the typical half cylinder configuration used for all meshes in the analysis. The blue rectangular border represents the original shape and the red mesh lines represent the 15-node triangular elements. The yellow line along the right edge represents the 5-node geogrid elements. The finite element model represents a one radian slice, which is rotated $2 \pi$ around the left edge or the axis of symmetry to trace the entire cylinder. 


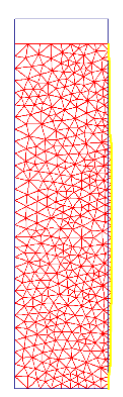

Figure 1. Typical mesh of the deformed shape (displacement $\times 10$ ) for half the $150 \mathrm{~mm} \times 300 \mathrm{~mm}$ cylinder with one wrap.

\subsection{Material Models}

The concrete was modeled as a Mohr-Coulomb material $[26,27,35,41,63]$ and the FRP as a linear elastic material. The Mohr-Coulomb material model is elastic, perfectly plastic and requires a total of five parameters. The material model was calibrated against actual test results [64] obtained by the authors on four standard cylinders of $150 \mathrm{~mm}$ in diameter and $300 \mathrm{~mm}$ in height, with an average 28 days compressive strength of $40 \mathrm{MPa}$ and one layer of Sika Wrap Hex 230C [62]. The calibrated parameters were Young's modulus $\left(=10,000 \mathrm{~N} / \mathrm{mm}^{2}\right)$, Poisson's ratio $(=0.2)$, the friction angle $\left(=35^{\circ}\right)$, cohesion $\left(=10.4 \mathrm{~N} / \mathrm{mm}^{2}\right)$ and the dilatancy angle $\left(=12^{\circ}\right)$. The FRP material model requires a single parameter, which is the product of the wrap's Young's modulus and the wrap's thickness $\left(=230,000 \mathrm{~N} / \mathrm{mm}^{2} \times\right.$ $0.13 \mathrm{~mm}$ per wrap) [62]. The ultimate strain of the FRP was taken as $1.5 \%$. Figure 2 shows the calibrated FEM model against the experimental data.

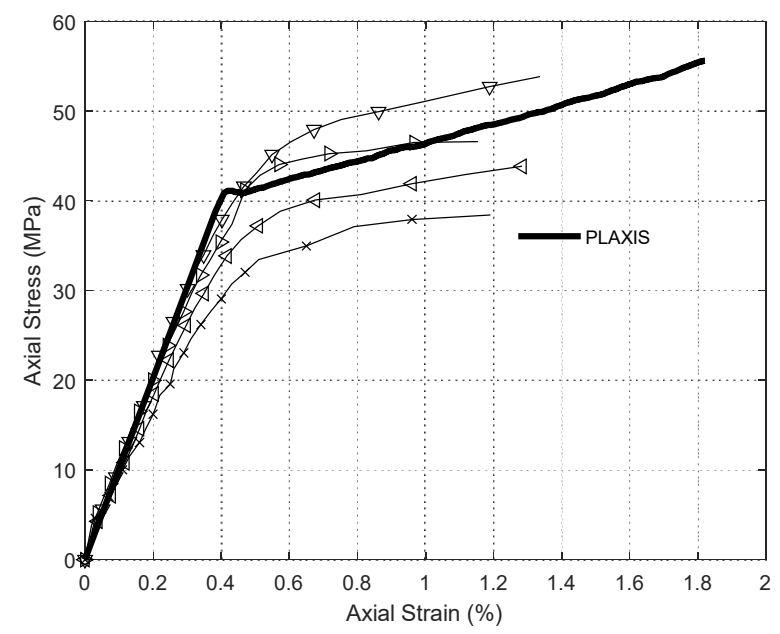

Figure 2. Comparison between the FEM model results and the experimental data from four different $40 \mathrm{MPa}$ standard $150 \mathrm{~mm} \times 300 \mathrm{~mm}$ concrete cylinders with one fiber reinforced plastics (FRP) wrap each.

\subsection{Boundary Conditions}

The loading was applied at the top end of the cylinder in the form of incremental uniform downward displacement. The lateral displacements at the top end and the displacements (lateral and vertical) at the bottom end were set to zero. These boundary conditions were selected to represent the actual conditions of high friction that develop between the ends of the loaded cylinders and the metallic loading platens [30-33]. 


\section{Results}

\subsection{The Stress-Strain Response}

The structural response of the finite element model was computed for the different parametric analyses and an average axial stress-axial strain relationship was plotted for each set of parameters. Failure of the system was defined as the point at which the peak hoop strain reaches the ultimate FRP strain of $1.5 \%$. Figures 3 and 4 compare the stress-strain responses of different combinations of cylinder slenderness and number of wraps.

The stress-strain response curves presented in Figures 3 and 4 capture the experimentally observed typical bi-linear behavior of the FRP-confined concrete. In the first part of the stress-strain curve, the behavior is linear, similar to that of the unconfined concrete. The second part shows a pseudo-plastic behavior, depending mainly on the FRP wrap's mechanical stiffness and the fracture mechanism developed inside the concrete core. If the stiffness of the wrap is sufficient, then this second part would consist of a linear ascending branch. The two linear parts are separated by a short transition zone, or a kink point, that corresponds to the localization of the failure inside the confined concrete and the development of a failure mechanism. The stress reached at the transition point is slightly larger than the unconfined compressive strength of the concrete used and depends on the stiffness of the confining device and the elastic properties of the concrete. The slope of the second part of the stress strain curve depends on the stiffness of the FRP wrap and the internal failure mechanism of the concrete dominated by the friction developed along the localized failure surfaces.

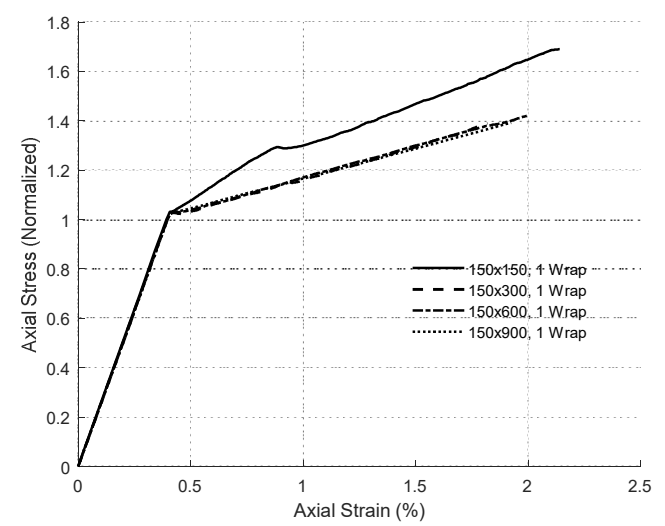

(a)

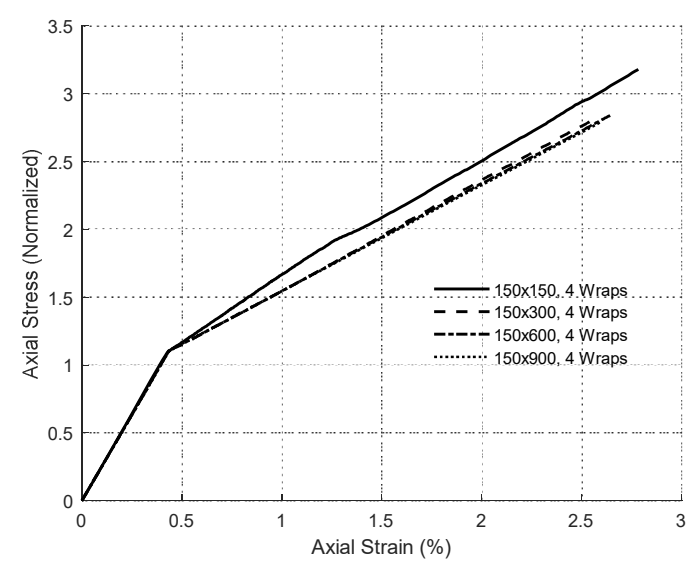

(c)

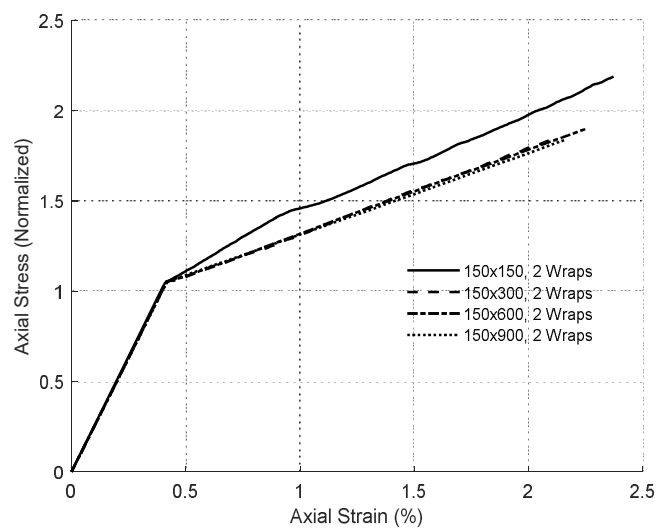

(b)

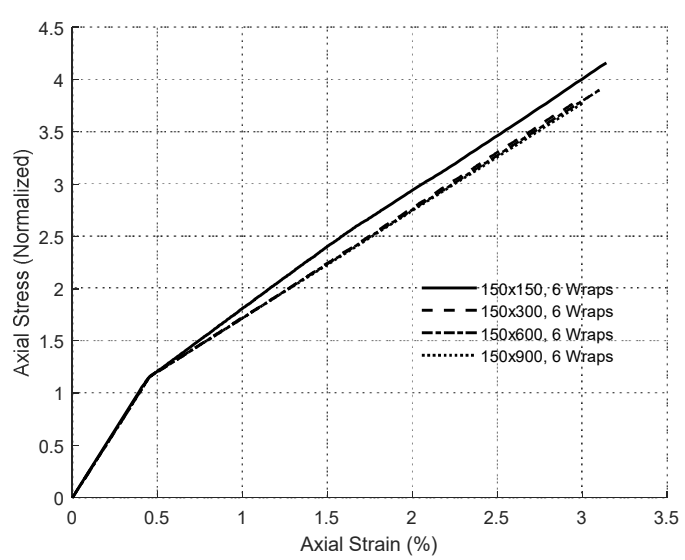

(d)

Figure 3. Effect of cylinder slenderness on the axial stress-axial strain response of concrete cylinders: (a) one FRP wrap, (b) two FRP wraps, (c) four FRP wraps, and (d) six FRP wraps. 


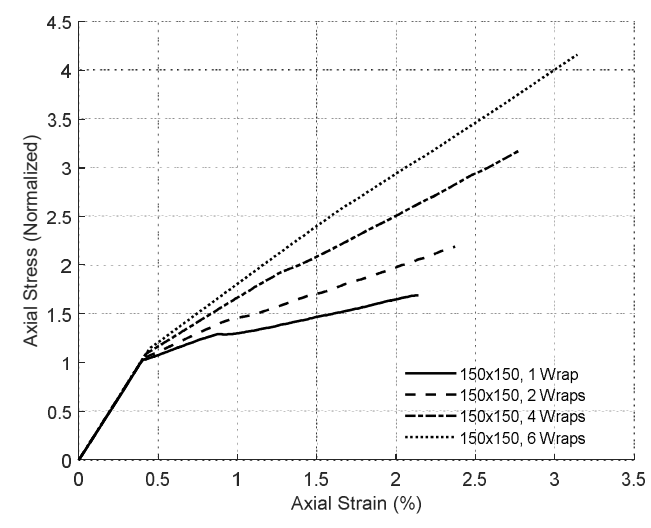

(a)

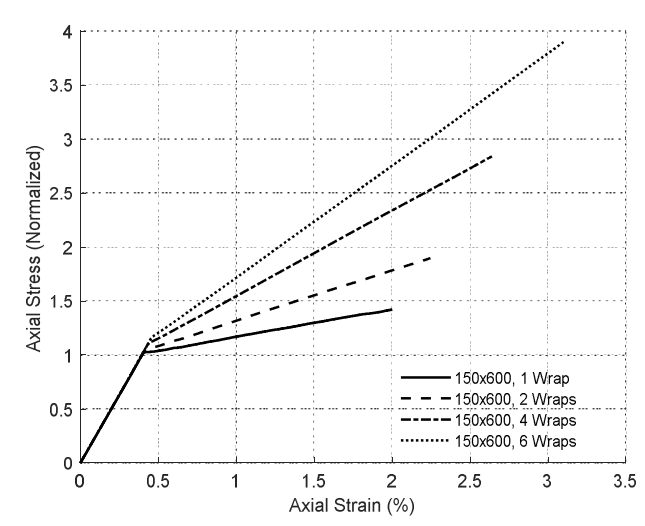

(c)

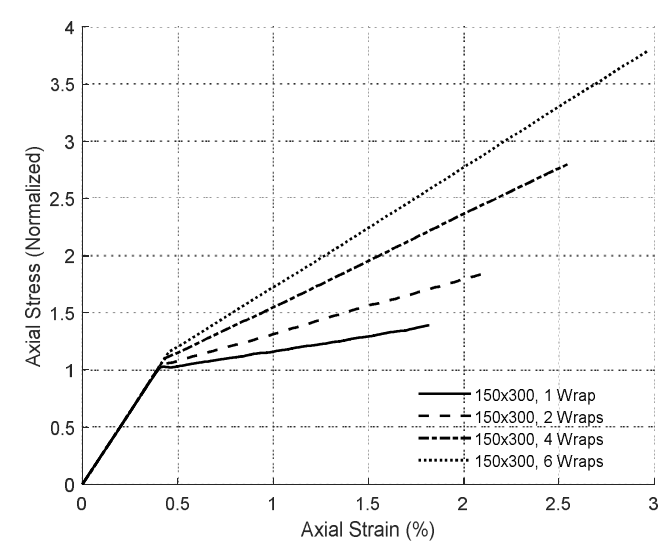

(b)

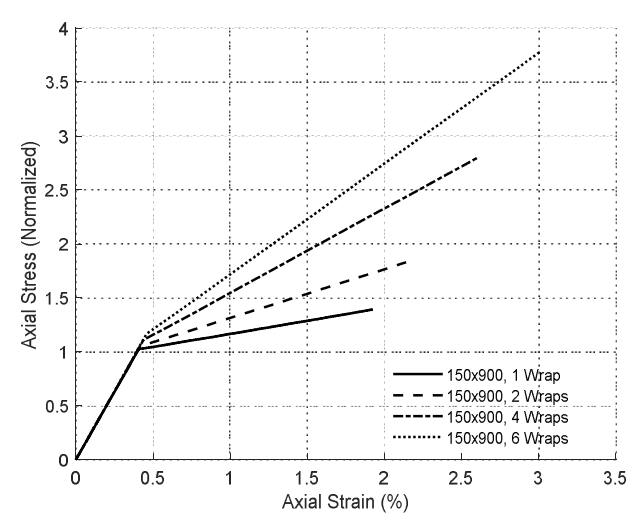

(d)

Figure 4. Effect of the number of wraps on the axial stress-axial strain response of concrete cylinders with varying slenderness (H/D): (a) $\mathrm{H} / \mathrm{D}=1,(\mathbf{b}) \mathrm{H} / \mathrm{D}=2$, (c) $\mathrm{H} / \mathrm{D}=4$, and (d) $\mathrm{H} / \mathrm{D}=6$.

In Figures 3 and 4, the stiffness of the response beyond the kink point increases with the number of wraps for all $\mathrm{H} / \mathrm{D}$ ratios. The kink point stress or transition zone stress increases slightly with the increase in the number of wraps or the shortening of the concrete cylinder. This is the point of failure localization inside the confined concrete when the appearance of fractured surfaces causes a sudden drop in the stiffness of the cylinder due to the loss of cohesion of the concrete mass and the external confining device is activated due to the internal sliding along these surfaces. The axial strain at the kink point is observed to increase from around $0.4 \%$ on average for cylinders with one wrap up to around $0.45 \%$ for cylinders with six wraps, consistent with elastic deformation theory. The normalized stress at the kink point is observed to increase with the number of wraps for cylinders with the same slenderness, reaching a maximum around 1.18 for cylinders with six wraps. The maximum axial strain and axial stress reached at the failure point of the confined system are observed to increase with the number of confining wraps.

\subsection{Effect of Slenderness}

With reference to Figure 3, it is noted that the stress-strain responses of the cylinders with slenderness ratios (H/D) of 2, 4 and 6, coincide for the same numbers of wraps, or level of confinement. The second branch of the stress-strain response of the cylinder with a slenderness ratio of 1 exhibits a higher stiffness than the other cylinders. This is due to the effect of the applied boundary conditions simulating the friction developed by the metallic loading platens in real experiments. Platen friction adds to the confinement of the concrete cylinder [30-33]. The limited height of the cylinder at H/D = 1 
is also seen to hinder the localization of a single fracture plane, causing multiple fracture planes to nucleate; thus, delaying the appearance of a failure mechanism.

\subsection{Effect of Number of Wraps}

Figure 4 compares the bi-linear stress-strain responses of cylinders of the same slenderness but with 1, 2, 4 and 6 CFRP wraps. It is noted that the higher the number of confining wraps, the stiffer is the second branch of the stress-strain response and the higher are the axial stress and strain before the failure of the CFRP. The second branch of the stress-strain response of the cylinder with a slenderness ratio $\mathrm{H} / \mathrm{D}=1$ exhibits a slight drop with softening, which corresponds to the development of a secondary localization mechanism penetrating all the way through the core of the short cylinder.

\subsection{Localization and Hoop Strain Profiles}

Figures 5-8 show the FEM mesh of the axisymmetric cross sections of the four sizes of cylinders considered, with one, two, four and six FRP wraps, plotted at the end of the stress-strain curves presented in Figures 3 and 4. The principal strains at each integration point are shown by a pair of vectors representing their orientation and magnitude, which clearly shows the localization of failure planes. The longer cylinders show multiple planes of failure with some planes more accentuated than others. Figures 5-8 also show the confining wrap hoop strain profiles plotted along the length of the cylinders at the point where the peak strain in the wraps reaches the ultimate strain of $1.5 \%$. It is assumed that the FRP wrap fails once the ultimate strain is reached at any location in the wrap.

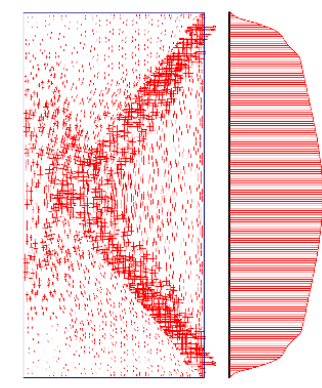

$150 \times 150,1$ wrap

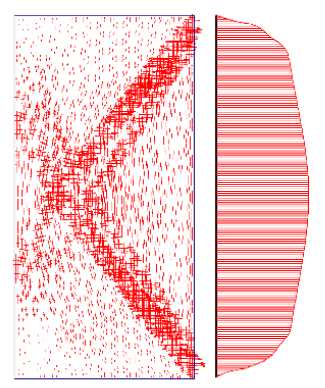

$150 \times 150,2$ wraps

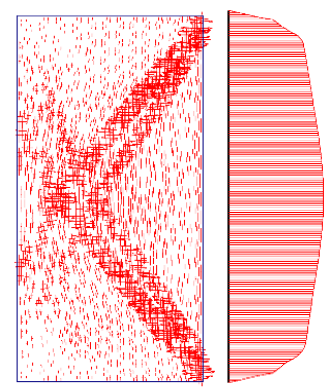

$150 \times 150,4$ wraps

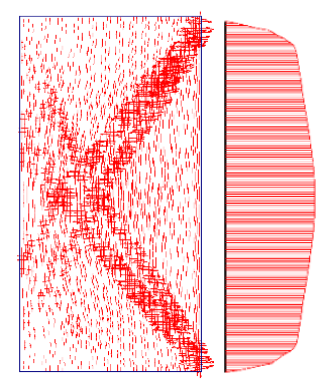

$150 \times 150,6$ wraps

Figure 5. Half cross-section of the $150 \mathrm{~mm} \times 150 \mathrm{~mm}$ cylinder with localized failure and the FRP wrap hoop strain profile at peak FRP strain $=1.5 \%$.

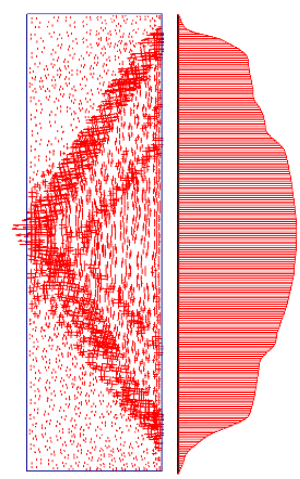

$150 \times 300,1$ wrap

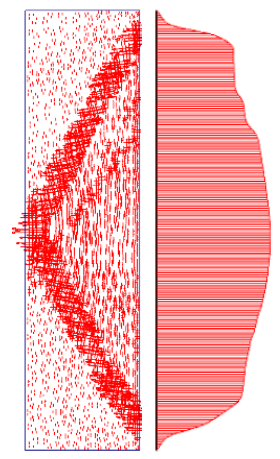

$150 \times 300,2$ wraps

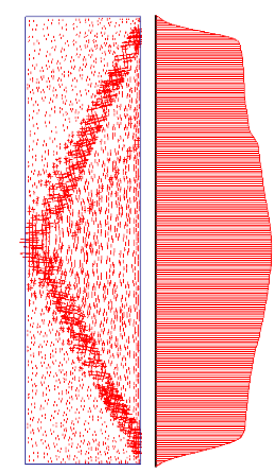

$150 \times 300,4$ wraps

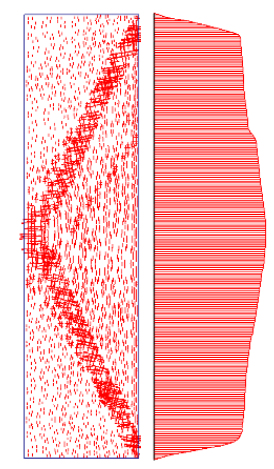

$150 \times 300,6$ wraps

Figure 6. Half cross-section of the $150 \mathrm{~mm} \times 300 \mathrm{~mm}$ cylinder with localized failure and the FRP wrap hoop strain profile at peak FRP strain $=1.5 \%$. 


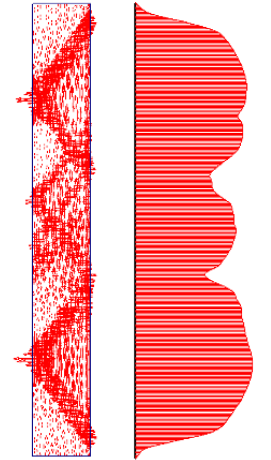

$150 \times 600,1$ wrap

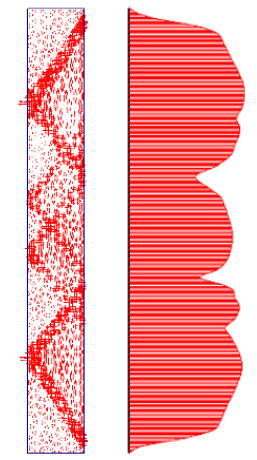

$150 \times 600,2$ wraps

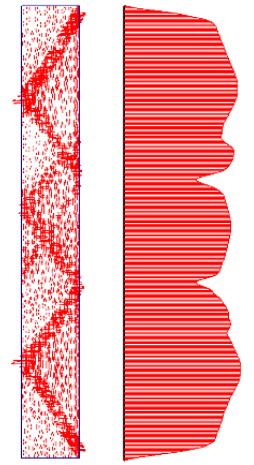

$150 \times 600,4$ wraps

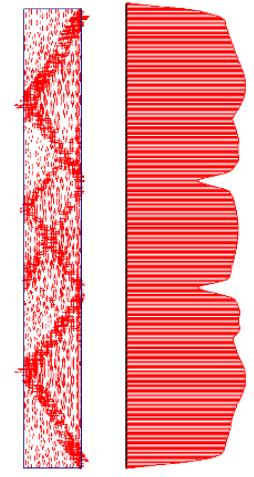

$150 \times 600,6$ wraps

Figure 7. Half cross-section of the $150 \mathrm{~mm} \times 600 \mathrm{~mm}$ cylinder with localized failure and the FRP wrap hoop strain profile at peak FRP strain $=1.5 \%$.

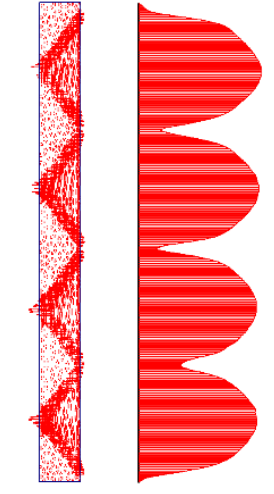

$150 \times 900,1$ wrap
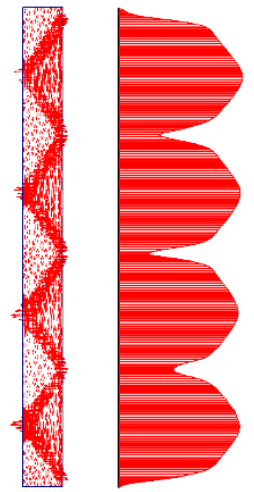

$150 \times 900,2$ wraps
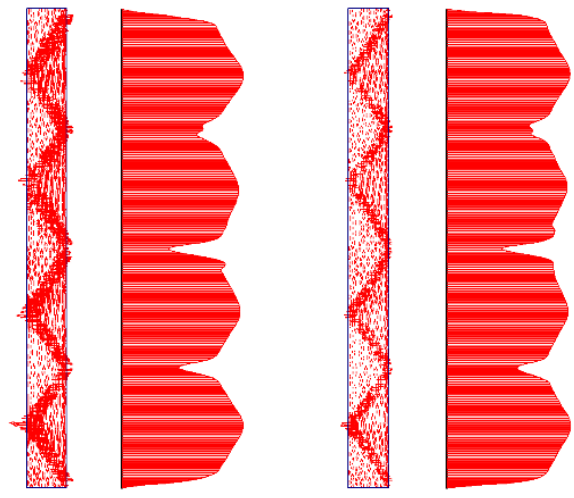

$150 \times 900,4$ wraps

$150 \times 900,6$ wraps

Figure 8. Half cross-section of the $150 \mathrm{~mm} \times 900 \mathrm{~mm}$ cylinder with localized failure and the FRP wrap hoop strain profile at peak FRP strain $=1.5 \%$.

The localized failure planes follow the same orientation for all configurations. It is observed that the proximity of the boundaries seems to constrain the failure planes in the shortest $\mathrm{H} / \mathrm{D}=1$ cylinders, causing a stiffer response and resulting in higher stress levels when compared to the longer cylinders. As failure planes localize at the specimen upper and lower corners and develop towards the center, they meet before reaching that center, leaving an intact core where additional failure planes can localize, requiring additional fracture energy. The levels of damage and the density of the highly strained elements increase with the confinement level or number of wraps.

The apparent ultimate strength and strain of the confined concrete system depend on the strength of the FRP wrap and the geometry of the mechanism of failure that causes strain concentrations in the wrap. After the localization of the failure planes inside the confined concrete, the movement of solid wedges along those planes causes high hoop stress concentrations in the FRP wrap. At the locations of maximum lateral displacement, the strain in the FRP wrap reaches its limit strength, causing premature failure of the confined cylinder. The hoop strain profiles in the FRP wraps plotted next to each cross-section in Figures 5-8 show the large stress variations caused by the localization of concrete failure and the movement of the solid wedges. The ratios of the average FRP hoop strain to the maximum hoop strain were calculated for all configurations, giving numbers between 0.692 and 0.874 , as shown in Table 1 alongside a summary of the results. 
Table 1. Axial and hoop stresses and strains, and the strain ratio.

\begin{tabular}{ccccccc}
\hline $\begin{array}{c}\text { Cylinder } \\
\text { Size }\end{array}$ & $\begin{array}{c}\text { Number of } \\
\text { Wraps }\end{array}$ & $\begin{array}{c}\text { Peak Axial } \\
\text { Normalized } \\
\text { Stress }\end{array}$ & $\begin{array}{c}\text { Peak Axial } \\
\text { Strain (\%) }\end{array}$ & $\begin{array}{c}\text { Average } \\
\text { Hoop Strain } \\
\mathbf{( \% )}\end{array}$ & $\begin{array}{c}\text { Maximum } \\
\text { Hoop Strain } \\
\mathbf{( \% )}\end{array}$ & $\begin{array}{c}\text { Hoop Strain } \\
\text { Ratio }\end{array}$ \\
\hline $150 \times 150$ & 1 & 1.69 & 2.14 & 1.20 & 1.52 & 0.790 \\
$150 \times 150$ & 2 & 2.19 & 2.37 & 1.24 & 1.52 & 0.815 \\
$150 \times 150$ & 4 & 3.18 & 2.78 & 1.27 & 1.52 & 0.838 \\
$150 \times 150$ & 6 & 4.16 & 3.14 & 1.27 & 1.51 & 0.846 \\
$150 \times 300$ & 1 & 1.39 & 1.82 & 1.05 & 1.52 & 0.692 \\
$150 \times 300$ & 2 & 1.85 & 2.11 & 1.15 & 1.52 & 0.758 \\
$150 \times 300$ & 4 & 2.80 & 2.54 & 1.22 & 1.52 & 0.801 \\
$150 \times 300$ & 6 & 3.79 & 2.96 & 1.27 & 1.52 & 0.832 \\
$150 \times 600$ & 1 & 1.42 & 2.00 & 1.18 & 1.52 & 0.774 \\
$150 \times 600$ & 2 & 1.90 & 2.25 & 1.23 & 1.52 & 0.812 \\
$150 \times 600$ & 4 & 2.84 & 2.64 & 1.27 & 1.52 & 0.837 \\
$150 \times 600$ & 6 & 3.90 & 3.10 & 1.33 & 1.52 & 0.874 \\
$150 \times 900$ & 1 & 1.39 & 1.93 & 1.13 & 1.52 & 0.742 \\
$150 \times 900$ & 2 & 1.84 & 2.16 & 1.18 & 1.52 & 0.777 \\
$150 \times 900$ & 4 & 2.80 & 2.60 & 1.25 & 1.52 & 0.822 \\
$150 \times 900$ & 6 & 3.78 & 3.01 & 1.29 & 1.52 & 0.848 \\
\hline
\end{tabular}

\section{Discussion}

\subsection{Localization and Characteristic Length}

Localization in compression is an applied fracture mechanics problem and has been observed to happen in concrete, among other materials [65-70].

Jansen and Shah [67] carried out an experimental investigation on compression failure localization in normal- and high-strength concrete cylinders with H/D ratios going from 2 to 5.5, reporting that the total length of the failure zone of the longer specimens became consistent at about three times the specimen diameter. In an extensive experimental study on localized failure in concrete specimens with $\mathrm{H} / \mathrm{D}$ ratios going from 2 to 8 , Watanabe et al. [34] identified three zones: (i) a failure zone (ii) a transition zone and (iii) an unloading zone. The length of the failure zone was found to be more or less constant of the order of $1.5 \mathrm{D}$, whereas the lengths of the transition and the unloading zones were found to be dependent on the slenderness ratio. In their proposal for a stress-strain model for uniaxial and confined concrete under compression, Samani and Attard [70] carried an extensive review of previous work, identifying the shortcomings. They proposed a new model that defines a characteristic length for the development of a Compression Damage Zone (CDZ), as defined by Markeset and Hillerborg [66], whereby this characteristic length was estimated at about 2.5 times the width of the specimen and the cracking displacement of the concrete specimen is mainly due to deformation in the localized shear band [71]. Dandapat et al. [42] verified the localization of failure in FRP-confined concrete cylinders, both experimentally and numerically. Wei and $\mathrm{Wu}$ [29] examined, experimentally, the localized failure in confined and unconfined concrete columns of $150 \mathrm{~mm}$ in diameter, with H/D going from 2 to 4.66 at six different levels of confinement. They confirmed the localization of failure and the development of a failure zone. They also observed that post peak deformation is independent of $\mathrm{H} / \mathrm{D}$ for ratios greater than two and proposed a new analytical stress-strain model that accounts for localization and calculates the length of the failure zone [72].

The results presented in Figures 5-8 agree well with the published literature on experimental observations and measurements and offer a qualitative explanation for the increase in compressive strength and the effects of the stiffness of the wrap [5,7-10,21,73-77]. The results indicate the existence of a characteristic length, Lc, independent of the level of confinement that is necessary for the localization and development of an unconstrained failure mechanism or solid wedge mechanism. This characteristic length is best seen when comparing the results for $\mathrm{H} / \mathrm{D}=4$ and $\mathrm{H} / \mathrm{D}=6$ between Figures 7 
and 8. The total length available in the $\mathrm{H} / \mathrm{D}=6$ specimen is sufficient to develop four successive mechanisms of length equal to the characteristic length giving $\mathrm{Lc} / \mathrm{D}=1.5$. Depending on the length of the confined concrete cylinder, a number of fully localized failure mechanisms can develop, each one of them then witnessing solid wedge movements along a shear frictional surface, causing stress concentrations in the FRP wrap and thus precipitating its premature failure. The total length available in the $\mathrm{H} / \mathrm{D}=4$ specimens is insufficient for the development of more than two full mechanisms, top and bottom, which initiate from the external contact points with the loading platens. In the central part, two minor mechanisms localize and overlap: one in continuation of the mechanism developing from the top, the other in continuation of the mechanisms developing from the bottom-neither one dominant. All of these mechanisms exhibit the same characteristic length, Lc. For the H/D $=2$ results presented in Figure 6, two major localized failure planes initiate from the external contact points with the loading platens similar to the $\mathrm{H} / \mathrm{D}=4$ specimens, but fail to develop two full overlapping mechanisms of length Lc, merging instead into one mechanism that is longer than Lc. Minor localization planes develop, mirroring the continuation of the critical length mechanisms as shown in Figure 9. The results for $\mathrm{H} / \mathrm{D}=1$ in Figure 5 reproduce the observed effects of the additional confinement created by the platen friction. Being shorter than Lc, a full mechanism cannot develop through its center; instead, the short cylinder develops a surface mechanism with $\mathrm{Lc} / \mathrm{D} \sim 1.5$, leaving a core inside the concrete cylinder that requires further loading before failure. This explains the higher strength and the different stress-strain response exhibited by the $\mathrm{H} / \mathrm{D}=1$ cylinder. The numerical model for $\mathrm{H} / \mathrm{D}=1$ agrees with and explains the observation of van Vliet and van Mier [32], in that the apparent strength of the concrete material increases with decreasing specimen size when conventional steel platens are used.

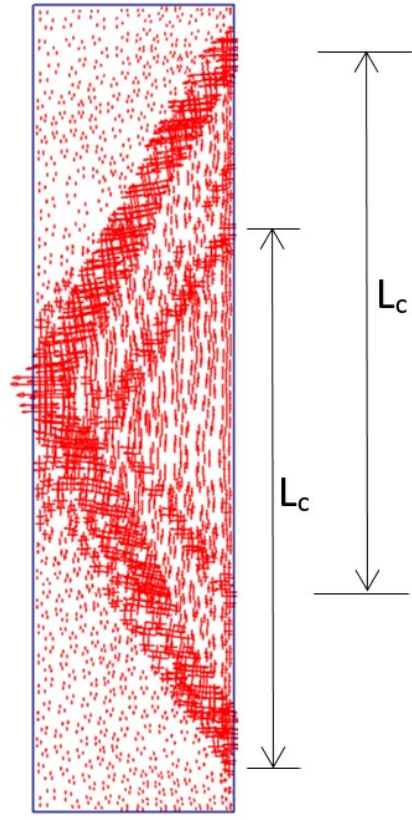

$150 \times 300$ (1 wrap)

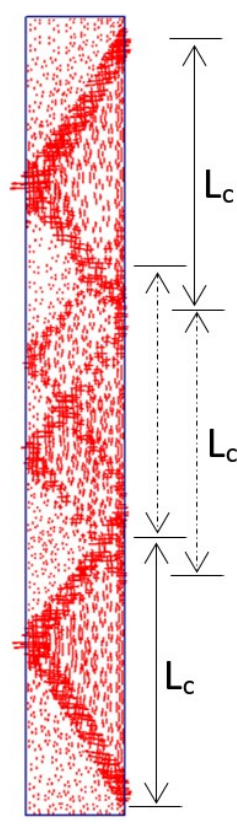

$150 \times 600$ (2 wraps)

Figure 9. Characteristic length, $\mathrm{Lc}$, and failure mechanisms for $\mathrm{H} / \mathrm{D}=2$ and $\mathrm{H} / \mathrm{D}=4$.

\subsection{Confinement Efficiency}

The ratio of the average FRP hoop strain to the maximum hoop strain that was calculated in Table 1 can be viewed as the efficiency factor of the FRP wrap relating the actual confinement stress to the theoretical one achievable when the whole wrap reaches its limit strain uniformly. The calculated values ranged between 0.692 and 0.874 and are in agreement with the observations and experimental results reported in the literature. Pessiki et al. [73] were among the first to introduce a strain efficiency factor accounting for the discrepancy between their experimental results and predictions. Based on their 
experimental observations, Fujikake et al. [13] proposed an empirical reduction factor of 0.5. Lam and Teng $[5,7]$ reported an efficiency factor of 0.586 based on the calibration of their experimental results on standard-size cylinders. Harries and Carey [74] computed 0.58 from a database of 251 test results, the majority of which pertain to standard-size cylinders. Carey and Harries [15] reported efficiency factors between 0.57 and 0.61 from the experimental results on small-, medium- and large-scale columns. Tabbara and Karam [6] had previously analyzed results from 19 published data sets that contain 192 data points and obtained a mean efficiency factor of 0.598 with a standard deviation of 0.248 . Ozbakkaloglu and Lim [75] analyzed 832 datasets collected from 99 experimental studies published between 1992 and mid-2013, and reported confinement efficiency factors between 0.675 and 0.709 . Benzaid and Mesbah [76] carried out an extensive investigation on the effects of various parameters on the efficiency of the FRP-confined concrete, covering their own experimental data [77] and others'. They reported an efficiency factor close to 0.73 for the circular specimens considered in their study.

The results of the parametric numerical modeling indicate that the confinement efficiency increases with the confining stiffness of the wrap, which agrees with experimental observations. Figure 10 shows the non-linear increase in the confinement efficiency with the number of confining FRP wraps for the various $\mathrm{H} / \mathrm{D}$ ratios; all calculated values are greater than the $\mathrm{ACI}$ recommended 0.55.

ACI 440.2R17 recommends one single conservative value of 0.55 for the efficiency factor in design Equation 12.1 [1], for all geometries and levels of confinement. The theoretical efficiency factor obtained from a numerical analysis, such as the one presented in this work, and a strength reduction factor can be employed in the formulation of an alternative design equation. Assuming, for example, a strength reduction factor of 0.75 , since fracture controls the failure of the FRP-confined concrete, then the recommended efficiency factor for a given confined concrete configuration would be equal to the value of the predicted confinement efficiency obtained from the numerical model for the corresponding geometry and confinement level multiplied by 0.75 . For example, assuming a confinement equivalent to six wraps, then the predicted confinement efficiency is 0.85 , which gives $0.75 \times 0.85=0.64$, and which is $16 \%$ higher than the ACI recommended value of 0.55 .

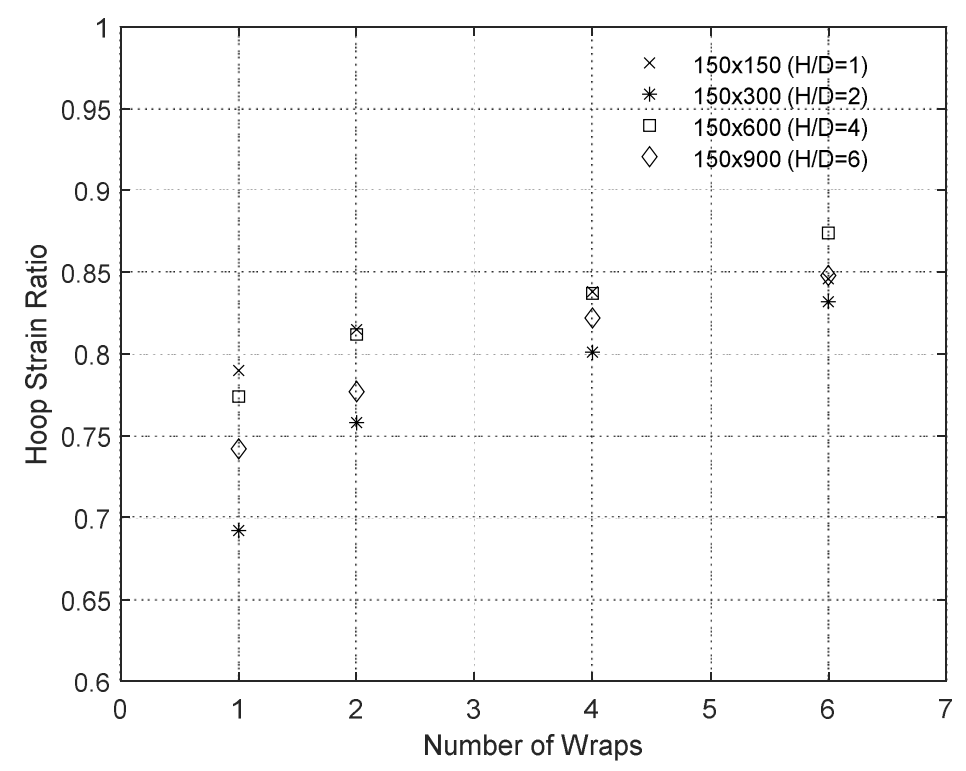

Figure 10. Confinement efficiency factor for various confinement levels and H/D ratios.

\subsection{Failure Mechanism and Proposed Rigid Block Model}

Figure 11 presents, for comparison with Figure 6, a failed 40 MPa concrete cylinder of $150 \mathrm{~mm} \times$ $300 \mathrm{~mm}$ with one CFRP wrap from the cylinders used to calibrate the model (refer to Section 2.3 and Figure 2). 


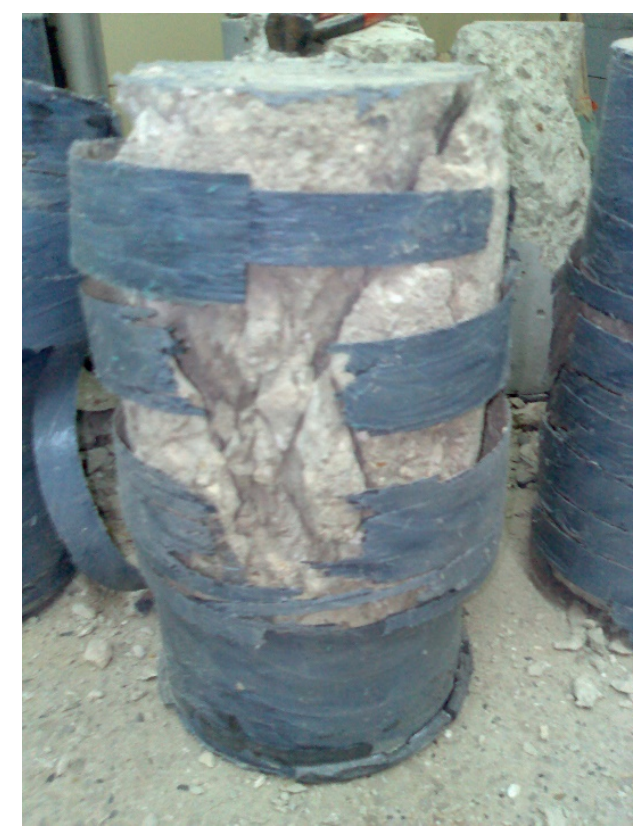

Figure 11. Photograph of a failed $150 \mathrm{~mm} \times 300 \mathrm{~mm}$ cylinder with $40 \mathrm{MPa}$ concrete and one CFRP wrap.

The failure planes, wedge mechanism and the CFRP failure pattern that can be observed in Figure 8 are all well captured by the numerical results presented in Figure 5 . The published literature contains a wealth of photos of similar experiments, showing the localized rupture of the FRP wraps and the development of a failure mechanism in the concrete cylinder, such as in Xiao and Wu [10], Wang and Wu [78], Bisby and Stratford [79], Chen et al. [20], Liang et al. [80] and Wei and Wu [29].

The response and failure of the confined concrete cylinders is characterized by the localization of failure and the formation of one or more inclined shear failure planes. This results in the separation of the concrete core into two or more wedges or blocks that form a failure mechanism. The movement of the broken wedges is laterally restrained in the presence of a lateral confinement device, such as hydraulic pressure, FRP wraps and steel stirrups. When the effect of lateral restraint is added up to the de-cohesion/localization response of the concrete, it results in a stable post peak behavior of the axially loaded concrete cylinder, such as indicated by the rising branch of the bi-linear stress-strain response in Figures 3 and 4. This post peak response is critical for the evaluation of the load-displacement behavior of confined concrete and to predict its failure load. A simple mechanistic model considering externally applied loads and internal reactions acting on an inclined crack was proposed by Harmon et al. (2002), similar to the mechanism shown in Figure 12 where the response of the model is controlled by the shear-friction on the sliding plane and the inclination of the failure angle $[26,27,35,63,81,82]$. Following Harmon et al. [83], Karam and Tabbara [81], Ali et al. [63] and Moran and Pantelides [26], an equation can be derived relating the increase in normalized residual axial stress, $\Delta \bar{\sigma}_{1}$, over the unconfined compressive strength, $f_{c o}^{\prime}$, to the normalized confining stress, $\bar{\sigma}_{3}$, using the coefficient of internal friction, $\mu$, and the angle of inclination of the sliding plane, $\varphi$, as

$$
\Delta \bar{\sigma}_{1}=\frac{\sin \varphi+\mu \cos \varphi}{(\cos \varphi-\mu \sin \varphi) \tan \varphi} \bar{\sigma}_{3}
$$

The normalized axial stress in the confined cracked concrete can then be found by

$$
\bar{\sigma}_{1}=1+\Delta \bar{\sigma}_{1}=1+\frac{\sin \varphi+\mu \cos \varphi}{(\cos \varphi-\mu \sin \varphi) \tan \varphi} \bar{\sigma}_{3}
$$




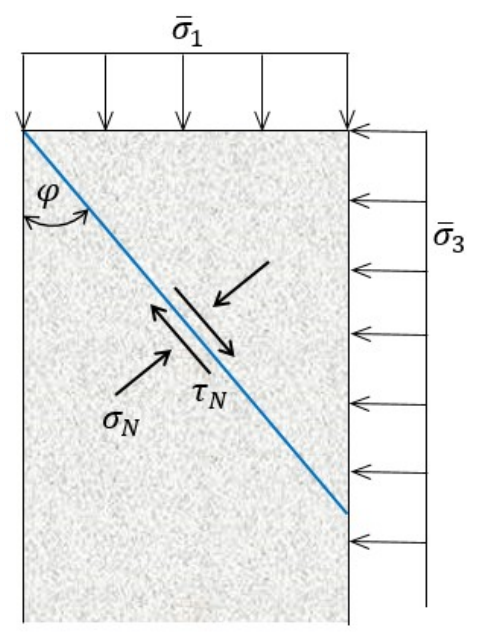

Figure 12. Shear-friction plane mechanism.

The coefficient of friction is a property of the concrete [81]; in the numerical model presented, the angle of friction was taken equal to $35^{\circ}$, hence $\mu=\tan (35)=0.7$. The failure angle can be measured from Figures $5-8$, and it varies depending on the geometry of the failure mechanism. For $\mathrm{L}_{\mathrm{c}} / D=1.5$, $\varphi=33.6^{\circ}$. Hence, Equation (2) can be calculated numerically as $\bar{\sigma}_{1}=1+3.84 \bar{\sigma}_{3}$ for the example at hand. Equation (2) follows the same shape as the one proposed by ACI 440.2R-17 [1]. The normalized confining stress of an FRP wrap is given by

$$
\bar{\sigma}_{3}=\frac{2 t}{D} \frac{E_{F R P}}{f_{c o}^{\prime}} \varepsilon_{F R P a v e}
$$

where $t$ is the total thickness of the FRP wrap, $D$ is the diameter of the concrete cylinder, $E_{F R P}$ is the modulus of elasticity of the FRP wrap, $f_{c o}^{\prime}$ is the unconfined compressive strength of the concrete and $\varepsilon_{F R P a v e}$ is the average hoop strain in the FRP wrap.

Equations (2) and (3) can then be used to predict the stress-strain response as well as the failure load of the confined concrete. With reference to the mechanism shown in Figure 13 for a confined cylinder, and making the following simplifying assumptions-(i) all displacements are small; (ii) the wedges are relatively rigid, so elastic deformations can be neglected; and (iii) the shear bands' width at the localized failure zones is very small-then, the vertical shortening, $\mathrm{u}$, can be related to geometry, $v$, the radial bulging through $v=u \tan \varphi$. The axial strain in the cylinder is then given by $\varepsilon_{1}=2 u / \mathrm{L}_{\mathrm{c}}$, where $L_{c}$ is the characteristic length. The radial strain in the confined cylinder is given by $\varepsilon_{3}=2 v / D$, where $D$ is the diameter of the cylinder. Noting that the radial strain and the hoop strain in the FRP are equal, we have $\varepsilon_{\text {FRPave }}=\varepsilon_{3}$ and combining the previous geometric relationships:

$$
\varepsilon_{\mathrm{FRPave}}=2 v / D=2 u \cdot \tan \varphi / D=\tan \varphi \cdot\left(\mathrm{L}_{\mathrm{c}} / D\right) \cdot \varepsilon_{1}
$$

Combining Equations (2)-(4):

$$
\bar{\sigma}_{1}=1+\frac{\sin \varphi+\mu \cos \varphi}{(\cos \varphi-\mu \sin \varphi) \tan \varphi} \frac{2 t}{D} \frac{E_{F R P}}{f_{c o}^{\prime}} \tan \varphi \cdot(\mathrm{Lc} / D) \cdot \varepsilon_{1}
$$

The proposed model presents a formal mechanical confirmation for the bi-linear model proposed in ACI 440.2R-17 based on the work of Lam and Teng [5,7] and offers a procedure for the calculation of the model parameters that are usually experimentally calibrated for each set of results. The normalized parameter of the bi-linear modulus of elasticity $\bar{E}_{2}$ can be calculated as

$$
\bar{E}_{2}=\frac{\sin \varphi+\mu \cos \varphi}{(\cos \varphi-\mu \sin \varphi) \tan \varphi} \frac{2 t}{D} \frac{E_{F R P}}{f_{c o}^{\prime}} \tan \varphi \cdot(\mathrm{Lc} / D)
$$


The normalized maximum confined compressive strength, $\bar{\sigma}_{C C}$, can also be calculated when $\varepsilon_{\mathrm{FRPave}}=\kappa \varepsilon_{\mathrm{FRPmax}}$ using the confinement efficiency factor, $\kappa$, presented in Figure 10:

$$
\bar{\sigma}_{C C}=1+\frac{\sin \varphi+\mu \cos \varphi}{(\cos \varphi-\mu \sin \varphi) \tan \varphi} \frac{2 t}{D} \frac{E_{F R P}}{f_{c o}^{\prime}} \cdot \kappa \varepsilon_{F R P \max }
$$

The calculation of $\bar{\sigma}_{C C}$, uses material properties and the final state of the strains in the wrap prior to failure; hence, producing a reliable value. Further work is needed for the fine tuning of the proposed stress-strain model and its application to the extensive data available in the literature, especially with respect to the simplifying assumptions made for its derivation $[84,85]$.

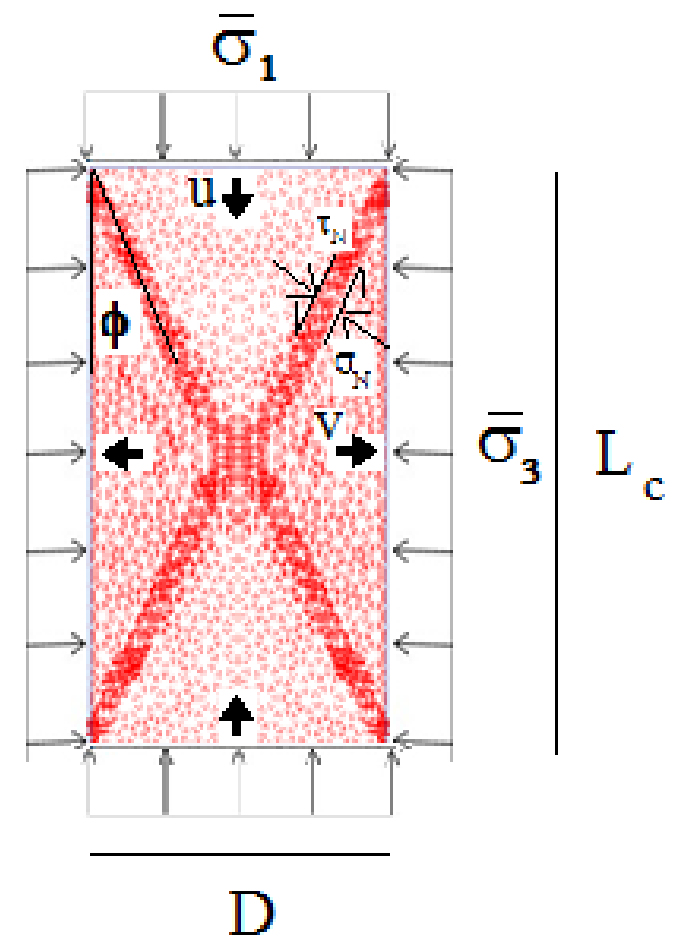

Figure 13. Failure mechanism in a confined concrete cylinder.

\section{Conclusions}

A simple axisymmetric finite element model was developed for FRP-wrapped concrete cylinders using the built-in capabilities of a commercial code, PLAXIS, and a Mohr-Coulomb constitutive material law. Without any particular modifications, the model was able to capture the failure localization in the confined concrete showing multiple failure planes and the development of a failure mechanism. The results indicate that the failure mode of the FRP-confined concrete is by localized rupture of the wrap due to extreme strains caused by the localization of failure inside the core.

A parametric analysis was carried out for four slenderness ratios, namely $\mathrm{H} / \mathrm{D}=1,2,4$ and 6 , and for four levels of CFRP confinement, corresponding to 1, 2, 4 and 6 wrap(s). The main observations were as follows:

- The stress-strain structural response curves capture the experimentally observed typical bi-linear behavior of the FRP-confined concrete. In the first part of the stress-strain curve, the behavior is linear similar to that of the unconfined concrete. The second part shows a pseudo-plastic linear behavior, depending mainly on the FRP wrap mechanical stiffness and the fracture mechanism developed inside the concrete.

- For a slenderness ratio H/D equal or greater than 2, the stress-strain responses of the cylinders coincide for the same level of confinement and fan up with increasing stiffness of the confining 
FRP. The response of the cylinders with $\mathrm{H} / \mathrm{D}=1$ is affected by the additional confinement caused by the friction between the loading platens and the concrete cylinder.

- The proposed numerical model captures the strain localization inside the concrete core and reflects that in the development of variable hoop stresses in the confining FRP along the length of the cylinders. Hoop stress profiles allow the prediction of the location of the premature failure of the FRP when its maximum strain is reached as well as the calculation of the average strain or confinement level in the confined system.

The results of the localization patterns indicate the existence of a characteristic length, Lc, independent of the level of confinement that is necessary for the localization and development of an unconstrained failure mechanism or solid wedge mechanism. This characteristic length, Lc, was estimated to be equal to 1.5D. These results concur with the findings published in the literature about localization in unconfined and confined concrete.

The efficiency factors of the FRP wrap, relating the actual confinement stress to the theoretical one achievable when the whole wrap uniformly reaches its limit strain, were calculated. The calculated values are weakly dependent on the slenderness but show a clear increasing trend with confinement stiffness increases, ranging between 0.692 and 0.874 . These values are in agreement with the results reported in the literature.

Using a shear-friction analysis approach, a simple rigid wedge mechanistic model is proposed. Equations are proposed that can be used to predict the failure load of the confined concrete as well as the stress-strain structural response of the confined system.

The proposed approach can be used to calculate the confinement efficiency factors for various geometries and to refine the design recommendations of ACI 440.2R17, such as in Equation 12.1 [1], by relating its parameters to independently measured material properties.

The sensitivity of the results reported in this work to variations in the properties of the FRP and concrete as well as the geometry of the confined cross sections requires further investigation. Further work is needed for the fine tuning of the proposed stress-strain model and its verification against the extensive data available in the literature.

Author Contributions: Conceptualization, G.K. and M.T.; methodology, G.K. and M.T.; software, M.T.; validation, M.T.; formal analysis, G.K. and M.T.; investigation, M.T.; resources, M.T.; writing—original draft preparation, G.K.; writing - review and editing, M.T. and G.K.; visualization, M.T. and G.K. All authors have read and agreed to the published version of the manuscript.

Funding: This research received no external funding.

Conflicts of Interest: The authors declare no conflict of interest.

\section{References}

1. American Concrete Institute (ACI) Committee 440. ACI-Report 440.2R-17: Design and Construction of Externally Bonded FRP Systems for Strengthening Concrete Structures; American Concrete Institute: Farmington Hills, MI, USA, 2017.

2. Canadian Standards Association (CSA). S806-12(R2017): Design and Construction of Building Structures with Fibre-Reinforced Polymers; Canadian Standards Association: Toronto, ON, Canada, 2017.

3. Teng, J.G.; Chen, J.F.; Smith, S.T.; Lam, L. FRP: Strengthened RC structures. Front. Phys. 2002, 1, 266.

4. De Lorenzis, L.; Tepfers, R. Comparative Study of Models on Confinement of Concrete Cylinders with Fiber-Reinforced Polymer Composites. J. Compos. Constr.-ASCE 2003, 7, 219-237. [CrossRef]

5. Lam, L.; Teng, J. Design-oriented stress-strain model for FRP-confined concrete. Constr. Build. Mater. 2003, 17, 471-489. [CrossRef]

6. Tabbara, M.R.; Karam, G.N. Modelling the strength of concrete cylinders confined with FRP wraps using the Hoek-brown strength criterion. In Proceedings of the 8th International Symposium on Fiber Reinforced Polymer Reinforcement for Concrete Structures, FRPRCS-8, University of Patras, Patras, Greece, 16-18 July 2007. 
7. Lam, L.; Teng, J. Design-Oriented Stress-Strain Model for FRP-Confined Concrete in Rectangular Columns. J. Reinf. Plast. Comp. 2003, 22, 1149-1186. [CrossRef]

8. Karbhari, V.M.; Gao, Y. Composite Jacketed Concrete under Axial Compression-Verification of Simple Design Equations. J. Mater. Civ. Eng.-ASCE 1997, 9, 185-193. [CrossRef]

9. Mirmiran, A.; Shahawy, M.; Samaan, M.; El Echary, H.; Mastrapa, J.C.; Pico, C. Effect of Column Parameters on FRP-Confined Concrete. J. Compos. Constr.-ASCE 1998, 2, 175-185. [CrossRef]

10. Xiao, Y.; Wu, H. Compressive Behavior of Concrete Confined by Carbon Fiber Composite Jackets. J. Mater. Civ. Eng.-ASCE 2000, 12, 139-146. [CrossRef]

11. Lam, L.; Teng, J.G. Strength Models for Fiber-Reinforced Plastic Confined Concrete. J. Struct. Eng.-ASCE 2002, 128, 612-623. [CrossRef]

12. Teng, J.G.; Lam, L. Behavior and Modeling of Fiber Reinforced Polymer Confined Concrete. J. Struct. Eng.-ASCE 2004, 130, 1713-1723. [CrossRef]

13. Fujikake, K.; Mindess, S.; Xu, H. Analytical Model for Concrete Confined with Fiber Reinforced Polymer Composite. J. Compos. Constr.-ASCE 2004, 8, 341-351. [CrossRef]

14. Karam, G.N.; Tabbara, M. Corner Effects in CFRP Wrapped Square Columns. Mag. Concr. Res. 2004, 56, 461-464. [CrossRef]

15. Carey, S.A.; Harries, K.A. Axial behavior and modeling of confined small-, medium-, and large-scale circular sections with carbon fiber-reinforced polymer jackets. ACI Struct. J. 2005, 102, 596.

16. Bisby, L.; Take, W.A.; Caspary, A. Quantifying strain variation in FRP confined concrete using digital image correlation: Proof-of-concept and initial results. In Proceedings of the 1st Asia-Pacific Conference on FRP in Structures, Department of Civil Engineering, University of Hong Kong, Hong Kong, China, 12-14 December 2007; pp. 599-604.

17. Bisby, L.A.; Take, W.A. Strain localisations in FRP-confined concrete: New insights. Proc. Inst. Civ. Eng.-Struct. Build. 2009, 162, 301-309. [CrossRef]

18. Smith, S.T.; Kim, S.J.; Zhang, H. Behavior and effectiveness of FRP wrap in the confinement of large concrete cylinders. J. Compos. Constr.-ASCE 2010, 14, 573-582. [CrossRef]

19. Abdelrahman, K.; El-Hacha, R. Behavior of large-scale concrete columns wrapped with CFRP and SFRP sheets. J. Compos. Constr.-ASCE 2011, 16, 430-439. [CrossRef]

20. Chen, J.F.; Li, S.Q.; Bisby, L.A. Factors affecting the ultimate condition of FRP-wrapped concrete columns. J. Compos. Constr.-ASCE 2012, 17, 67-78. [CrossRef]

21. El-Hacha, R.; Abdelrahman, K. Slenderness effect of circular concrete specimens confined with SFRP sheets. Compos. B Eng. 2013, 44, 152-166. [CrossRef]

22. Wu, Y.F.; Jiang, J.F. Effective strain of FRP for confined circular concrete columns. Compos. Struct. 2013, 95, 479-491. [CrossRef]

23. Salameh, N.; El-Hacha, R.; Abdelrahman, K. Evaluation of Axial and Lateral Strain Variation and Efficiency in CFRP-Confined Concrete Cylinders. In Proceedings of the 12th International Symposium on Fiber Reinforced Polymers for Reinforced Concrete Structures (FRPRCS-12) \& The 5th Asia-Pacific Conference on Fiber Reinforced Polymers in Structures (APFIS-2015) Joint Conference, Nanjing, China, 14-16 December 2015.

24. Lim, J.C.; Ozbakkaloglu, T. Hoop strains in FRP-confined concrete columns: Experimental observations. Mater. Struct. 2015, 48, 2839-2854. [CrossRef]

25. Teng, J.G.; Wu, J.Y.; Casalboni, S.; Xiao, Q.G.; Zhao, Y. Behavior and modeling of fiber-reinforced polymer-confined concrete in elliptical columns. Adv. Struct. Eng. 2016, 19, 1359-1378. [CrossRef]

26. Moran, D.A.; Pantelides, C.P. Elliptical and circular FRP-confined concrete sections: A Mohr-Coulomb analytical model. Int. J. Solids Struct. 2012, 49, 881-898. [CrossRef]

27. Moran, D.A.; Pantelides, C.P.; Reaveley, L.D. Mohr-coulomb model for rectangular and square FRP-confined concrete. Compos. Struct. 2019, 209, 889-904. [CrossRef]

28. Tabbara, M.; Karam, G. Numerical investigation of failure localization and stress concentrations in FRP wrapped concrete cylinders. In Proceedings of the 5th International Conference on Advanced Composite Materials in Bridges and Structures (ACMBS-V), Winnipeg, MB, Canada, 22-24 September 2008.

29. Wei, Y.; Wu, Y.F. Experimental study of concrete columns with localized failure. J. Compos. Constr. 2016, 20, 04016032. [CrossRef]

30. Kotsovos, M.D. Effect of testing techniques on the post-ultimate behaviour of concrete in compression. Mat. Constr. 1983, 16, 3-12. [CrossRef] 
31. Van Mier, J.G.M. Strain-Softening of Concrete under Multiaxial Loading Conditions. Ph.D. Thesis, Technische Hogeschool Eindhoven, Eindhoven, The Netherlands, 1984; pp. 32-39.

32. Van Vliet, M.A.; Van Mier, J.M. Experimental investigation of concrete fracture under uniaxial compression. Mech. Cohesive Frict. Mater. 1996, 1, 115-127. [CrossRef]

33. Aulia, T.B. Strain localization and fracture energy of high strength concrete under uniaxial compression. Leipz. Annu. Civ. Eng. Rep. Lacer 2000, 5, 221-240.

34. Watanabe, K.; Niwa, J.; Yokota, H.; Iwanami, M. Experimental study on stress-strain curve of concrete considering localized failure in compression. J. Adv. Concr. Tech. 2004, 2, 395-407. [CrossRef]

35. Van Mier, J.G. Mode II fracture localization in concrete loaded in compression. J. Eng. Mech.-ASCE 2009, 135, 1-8. [CrossRef]

36. Marques, S.P.C.; Marques, D.C.D.S.C.; Lins da Silva, J.; Cavalcante, M.A.A. Model for analysis of short columns of concrete confined by fiber-reinforced polymer. J. Compos. Constr. 2004, 8, 332-340. [CrossRef]

37. Malvar, L.J.; Morrill, K.B.; Crawford, J.E. Numerical modeling of concrete confined by fiber-reinforced composites. J. Compos. Constr. 2004, 8, 315-322. [CrossRef]

38. Karabinis, A.I.; Rousakis, T.C.; Manolitsi, G.E. 3D finite-element analysis of substandard RC columns strengthened by fiber-reinforced polymer sheets. J. Compos. Constr. 2008, 12, 531-540. [CrossRef]

39. Wu, H.L.; Wang, Y.F.; Yu, L.; Li, X.R. Experimental and computational studies on high-strength concrete circular columns confined by aramid fiber-reinforced polymer sheets. J. Compos. Constr. 2009, 13, 125-134. [CrossRef]

40. Yu, T.; Teng, J.G.; Wong, Y.L.; Dong, S.L. Finite element modeling of confined concrete-I: Drucker-Prager type plasticity model. Eng. Struct. 2010, 32, 665-679. [CrossRef]

41. Galic, M.; Marovic, P.; Nikolic, Z. Modified Mohr-Coulomb-Rankine material model for concrete. Eng. Comput. 2011, 28, 853-887. [CrossRef]

42. Dandapat, R.; Deb, A.; Bhattacharyya, S.K. Localized failure in fiber-reinforced polymer-wrapped cylindrical concrete columns. ACI Struct. J. 2012, 109, 445.

43. Carrazedo, R.; Mirmiran, A.; de Hanai, J.B. Plasticity based stress-strain model for concrete confinement. Eng. Struct. 2013, 48, 645-657. [CrossRef]

44. Tao, Z.; Wang, Z.B.; Yu, Q. Finite element modelling of concrete-filled steel stub columns under axial compression. J. Constr. Steel Res. 2013, 89, 121-131. [CrossRef]

45. Youssef, O.; El Gawady, M.A.; Mills, J.E.; Ma, X. Finite element modelling and dilation of FRP-confined concrete columns. Eng. Struct. 2014, 79, 70-85. [CrossRef]

46. Gambarelli, S.; Nisticò, N.; Ožbolt, J. Numerical analysis of compressed concrete columns confined with CFRP: Microplane-based approach. Compos. B Eng. 2014, 67, 303-312. [CrossRef]

47. Kwan, A.K.H.; Dong, C.X.; Ho, J.C.M. Axial and lateral stress-strain model for FRP confined concrete. Eng. Struct. 2015, 99, 285-295. [CrossRef]

48. Mostofinejad, D.; Moshiri, N.; Mortazavi, N. Effect of corner radius and aspect ratio on compressive behavior of rectangular concrete columns confined with CFRP. Mater. Struct. 2015, 48, 107-122. [CrossRef]

49. Lo, S.H.; Kwan, A.K.H.; Ouyang, Y.; Ho, J.C.M. Finite element analysis of axially loaded FRP-confined rectangular concrete columns. Eng. Struct. 2015, 100, 253-263. [CrossRef]

50. Ozbakkaloglu, T.; Gholampour, A.; Lim, J.C. Damage-plasticity model for FRP-confined normal-strength and high-strength concrete. J. Compos. Constr. 2016, 20, 04016053. [CrossRef]

51. Hany, N.F.; Hantouche, E.G.; Harajli, M.H. Finite element modeling of FRP-confined concrete using modified concrete damaged plasticity. Eng. Struct. 2016, 125, 1-14. [CrossRef]

52. Lim, J.C.; Ozbakkaloglu, T.; Gholampour, A.; Bennett, T.; Sadeghi, R. Finite-element modeling of actively confined normal-strength and high-strength concrete under uniaxial, biaxial, and triaxial compression. J. Struct. Eng.-ASCE 2016, 142, 04016113. [CrossRef]

53. Farahmandpour, C.; Dartois, S.; Quiertant, M.; Berthaud, Y.; Dumontet, H. A concrete damage-plasticity model for FRP confined columns. Mater. Struct. 2017, 50, 156. [CrossRef]

54. Jamatia, R.; Deb, A. Size Effect in FRP-Confined Concrete under Axial Compression. J. Compos. Constr. 2017, 21, 1-15. [CrossRef]

55. Chellapandian, M.; Prakash, S.S.; Rajagopal, A. Analytical and finite element studies on hybrid FRP strengthened RC column elements under axial and eccentric compression. Compos. Struct. 2018, 184, $234-248$. [CrossRef] 
56. Ribeiro, F.; Sena-Cruz, J.; Branco, F.G.; Júlio, E. 3D finite element model for hybrid FRP-confined concrete in compression using modified CDPM. Eng. Struct. 2019, 190, 459-479. [CrossRef]

57. Wang, X.; Qi, Y.; Sun, Y.; Xie, Z.; Liu, W. Compressive behavior of composite concrete columns with encased FRP confined concrete cores. Sensors 2019, 19, 1792. [CrossRef]

58. Jamatia, R.; Deb, A. FRP confined hollow concrete columns under axial compression: A comparative assessment. Compos. Struct. 2020, 236, 111857. [CrossRef]

59. Raza, A.; Shah, S.A.R.; Khan, A.R.; Aslam, M.A.; Khan, T.A.; Arshad, K.; Waseem, M. Sustainable FRP-confined symmetric concrete structures: An application experimental and numerical validation process for reference data. Appl. Sci. 2020, 10, 333. [CrossRef]

60. Saberi, H.; Bui, T.Q.; Furukawa, A.; Rahai, A.; Hirose, S. FRP-confined concrete model based on damage-plasticity and phase-field approaches. Compos. Struct. 2020, 244, 112263. [CrossRef]

61. PLAXIS V8, PLAXIS bv P.O. Box 572, 2600 AN DELFT, Netherlands. 2008.

62. Sika Construction Data Book; Sika Near East, S.A.L. Member of the Sika Group: Beirut, Lebanon, 2002.

63. Ali, M.M.; Oehlers, D.J.; Griffith, M.C. The residual strength of confined concrete. Adv. Struct. Eng. 2010, 13, 603-618. [CrossRef]

64. Ardiaca, D.H. Mohr-Coulomb Parameters for Modelling of Concrete Structures. Plaxis Bull. 2009, 25, 12-15, Spring issue.

65. Bažant, Z.P. Identification of strain-softening constitutive relation from uniaxial tests by series coupling model for localization. Cem. Concr. Res. 1989, 19, 973-977. [CrossRef]

66. Markeset, G.; Hillerborg, A. Softening of concrete in compression-localization and size effects. Cem. Concr. Res. 1995, 25, 702-708. [CrossRef]

67. Jansen, D.C.; Shah, S.P. Effect of length on compressive strain softening of concrete. J. Eng. Mech.-ASCE 1997, 123, 25-35. [CrossRef]

68. Nakamura, H.; Higai, T. Compressive fracture energy and fracture zone length of concrete. In Modeling of Inelastic Behavior of RC Structures under Seismic Loads; Benson Shing, P., Tada-aki, T., Eds.; ASCE Publications: Reston, VA, USA, 2001; pp. 471-487.

69. Kim, J.K.; Yi, S.T. Application of size effect to compressive strength of concrete members. Sadhana 2002, 27, 467. [CrossRef]

70. Samani, A.K.; Attard, M.M. A stress-strain model for uniaxial and confined concrete under compression. Eng. Struct. 2012, 41, 335-349. [CrossRef]

71. Carpinteri, A.; Corrado, M.; Paggi, M. An analytical model based on strain localisation for the study of size-scale and slenderness effects in uniaxial compression tests. Strain 2011, 47, 351-362. [CrossRef]

72. Wu, Y.F.; Wei, Y. Stress-Strain Modeling of Concrete Columns with Localized Failure: An Analytical Study. J. Compos. Constr. 2015, 20, 04015071. [CrossRef]

73. Pessiki, S.; Harries, K.A.; Kestner, J.T.; Sause, R.; Ricles, J.M. Axial behavior of reinforced concrete columns confined with FRP jackets. J. Compos. Constr. 2001, 5, 237-245. [CrossRef]

74. Harries, K.A.; Carey, S.A. Shape and "gap" effects on the behavior of variably confined concrete. Cem.Concr. Res. 2003, 33, 881-890. [CrossRef]

75. Ozbakkaloglu, T.; Lim, J.C. Axial compressive behavior of FRP-confined concrete: Experimental test database and a new design-oriented model. Compos. B Eng. 2013, 55, 607-634. [CrossRef]

76. Benzaid, R.; Mesbah, H. AThe confinement of concrete in compression using CFRP composites-effective design equations. J. Civ. Eng. Manag. 2014, 20, 632-648. [CrossRef]

77. Chikh, N.; Benzaid, R.; Mesbah, H. An experimental investigation of circular RC columns with various slenderness confined with CFRP sheets. Arab. J. Sci. Eng. 2012, 37, 315-323. [CrossRef]

78. Wang, Y.F.; Wu, H.L. Size effect of concrete short columns confined with aramid FRP jackets. J. Compos. Constr. 2010, 15, 535-544. [CrossRef]

79. Bisby, L.A.; Stratford, T.J. The ultimate condition of FRP confined concrete columns: New experimental observations and insights. In Advances in FRP Composites in Civil Engineering; Springer: Berlin/Heidelberg, Germany, 2011; pp. 599-602.

80. Liang, M.; Wu, Z.M.; Ueda, T.; Zheng, J.J.; Akogbe, R. Experiment and modeling on axial behavior of carbon fiber reinforced polymer confined concrete cylinders with different sizes. J. Reinf. Plast. Compos. 2012, 31, 389-403. [CrossRef] 
81. Karam, G.; Tabbara, M. Hoek-Brown strength criterion for actively confined concrete. J. Mater. Civ. Eng. 2009, 21, 110-118. [CrossRef]

82. Haskett, M.; Oehlers, D.J.; Ali, M.M.; Sharma, S.K. Evaluating the shear-friction resistance across sliding planes in concrete. Eng. Struct. 2011, 33, 1357-1364. [CrossRef]

83. Harmon, T.G.; Gould, N.C.; Ramakrishnan, S.; Wang, E.H. Confined concrete columns subjected to axial load, cyclic shear, and cyclic flexure-Part I: Analytical models. ACI Struct. J. 2002, 99, 32-41.

84. Montuori, R.; Piluso, V.; Tisi, A. Comparative analysis and critical issues of the main constitutive laws for concrete elements confined with FRP. Compos. B Eng. 2012, 43, 3219-3230. [CrossRef]

85. Montuori, R.; Piluso, V.; Tisi, A. Ultimate behaviour of FRP wrapped sections under axial force and bending: Influence of stress-strain confinement model. Compos. B Eng. 2013, 54, 85-96. [CrossRef]

(C) 2020 by the authors. Licensee MDPI, Basel, Switzerland. This article is an open access article distributed under the terms and conditions of the Creative Commons Attribution (CC BY) license (http://creativecommons.org/licenses/by/4.0/). 